\title{
Liking, salt taste perception and use of table salt when consuming reduced- salt chicken stews in light of South Africa's new salt regulations
}

De Kock H.L. ${ }^{a^{*}}$, Zandstra E.H. ${ }^{b}$, Sayed N. ${ }^{c}$, Wentzel-Viljoen E. ${ }^{d, e}$

$a^{a^{*}}$ Dept. of Food Science, University of Pretoria, Private bag X20, Hatfield, Pretoria South Africa 0002

${ }^{b}$ Consumer Science, Unilever R\&D Vlaardingen, The Netherlands

${ }^{c}$ Nutrition \& Health, Unilever South Africa, South Africa

${ }^{d}$ Centre of Excellence for Nutrition, North-West University, Private bag X6001, Potchefstroom South Africa 2520

${ }^{e}$ Medical Research Council Research Unit for Hypertension and Cardiovascular Disease, Faculty of Health Sciences, North-West University, Private bag X6001, Potchefstroom, South Africa 2520

${ }^{*}$ Corresponding author:

H.L. de Kock, Dept. of Food Science, University of Pretoria, Private bag X20, Hatfield, Pretoria South Africa 0002 riette.dekock@up.ac.za +27 124203238

\section{Highlights}

- New consumer-focused behaviour insights for salt reduction of meals.

- Unexpected similarities in liking for chicken meals with varying levels of salt.

- A gradual reduction of salt in chicken stews resulted in a reduced salt intake.

- $19 \%$ consumers added salt back to reduced-salt meals, up to full compensation.

\begin{abstract}
This study investigated the impact of salt reduction on liking, salt taste perception, and use of table salt when consuming chicken stew in light of South Africa"s new salt recommendations. In total, 432 South-African consumers (aged $35.2 \pm 12.3$ years) consumed a full portion of a chicken stew meal once at a central location. Four stock cube powders varying in salt content were used to prepare chicken stews: 1) no reduction - $2013 \mathrm{Na}$ level; regular salt level as currently available on the South African market (24473 mg Na/100g), 2) salt reduction smaller than 2016 level, i.e. $10 \%$-reduced (22025 mg Na/100g), 3) 2016 salt level, as per regulatory prescriptions (18000 mg Na/100g), 4) 2019 salt level, as per regulatory prescriptions (13000 mg $\mathrm{Na} / 100 \mathrm{~g}$ ). Consumers were randomly allocated to consume one of the four meals. Liking, salt taste perception, and use of table salt and pepper were measured.
\end{abstract}


Chicken stews prepared with reduced-salt stock powders were equally well-liked as chicken stews with the current salt level. Moreover, a gradual reduction of the salt in the chicken stews resulted in a reduced salt intake, up to an average of $19 \%$ for the total group compared to the benchmark $2013 \mathrm{Na}$ level stew. However, 19\% of consumers compensated by adding salt back to full compensation in some cases. More salt was added with increased reductions of salt in the meals, even to the point of full compensation. Further investigation into the impacts of nutrition communication and education about salt reduction on salt taste perception and use is needed. This research provides new consumer insights on salt use and emphasises the need for consumer-focused behaviour change approaches, in addition to reformulation of products.

\section{Introduction}

Globally, current salt (sodium chloride: $\mathrm{NaCl}$ ) intake is on average much higher than the recommended World Health Organization (WHO) level of 5 grams of salt (2000mg sodium) per day (Brown, Tzoulaki, Candeias, \& Elliott, 2009; World Health Organisation, 2012). Excessive intake of dietary salt is a major contributor to cardiovascular diseases and stroke as it progressively raises blood pressure levels with age (He \& MacGregor, 2003, 2010; Mohan \& Campbell, 2009). Reducing sodium intake to $1500-2300 \mathrm{mg}$ per day ( $3.75-5.75 \mathrm{~g}$ salt/day) could lead to major improvements in cardiovascular health (Cook, Appel, \& Whelton, 2014). In countries where effective salt reduction programmes were implemented, the prevalence of high blood pressure and cardiovascular diseases significantly decreased $(\mathrm{He} \&$ MacGregor, 2009; Sutherland, Edwards, Shankar, \& Dangour, 2013; Webster, Dunford, Hawkes, \& Neal, 2011). It has also been suggested that reducing salt intake is the most cost-effective way of managing hypertension (Bertram, Steyn, WentzelViljoen, Tollman, \& Hofman, 2012; Bibbins-Domingo et al., 2010; Cobiac, Vos, Veerman, 2010).

Total dietary salt intake is derived from three sources, namely: 1) commercially prepared or manufactured foods (e.g. bread, soup, snacks, olives and restaurant meals), 2) that which occurs naturally in foods, and 3) as discretionary salt (i.e. added by consumers at the table and/or during cooking). Most of the salt intake comes through consumption of commercially prepared or manufactured food products, but there are significant variations between countries (James, Ralph, \& Sanchez-Castillo, 1987; Mattes \& Donnelly, 1991). Discretionary salt is only $5-10 \%$ of total salt intake in the USA (Mattes \& Donnelly, 1991), while in South Africa it is far higher at $32.8 \%, 42.2 \%$ and $45.5 \%$ for white, mixed ancestry, and black consumers 
respectively (Charlton et al., 2005). Thus far, the industry in some countries has already successfully lowered salt levels in many commercial foods (Dötsch et al., 2009; Webster et al., 2011; World Health Organisation, 2007) -- without the consumer being aware of this. Nevertheless, the need for more salt reduction in consumer products remains pressing.

In South Africa (SA), the SA Hypertension Guidelines recommend a salt intake of less than $6 \mathrm{~g} /$ day ( $\mathrm{Na} 2400 \mathrm{mg} /$ day), based on the upper boundary of the recommended WHO level of 5-6 g/day (Seedat \& Rayner, 2012). The average salt intake of South African adults, as measured by 24-hour urine sodium excretion, is between nearly 6 and $10 \mathrm{~g} /$ day (Barlow, Connell, \& Levendig, 1982; Charlton et al., 2005; Hoosen, Seedat, \& Bhigjee, 1990; Norton \& Woodiwiss, 2011). To reduce dietary salt consumption, the South African government has published mandatory regulations for the gradual reduction of salt over a period of six years in different commercial food categories, which come into effect in 2016 and 2019 (Department of Health, 2013). These food categories cover a range of food products: breads, meats, cereal products, fat spreads, snack foods and savoury products used in cooking. They were selected based on their contribution to salt intake. It is envisaged that limiting salt intake from these products will contribute to lowering blood pressure, which could significantly lower cardiovascular diseases in South Africa and hence will contribute to substantial health care savings. However, legislating salt levels in commercial foods is only one part of a national strategy. It is important for health professionals and educators to also provide appropriate practical nutrition education and promotion that will educate, motivate and enable consumers to change their dietary behaviour in a more healthy direction (Newson et al., 2013; Wentzel-Viljoen, Steyn, Ketterer, \& Charlton, 2013). In addition, it is important to consider the impact of salt reduction on taste perception and liking of reduced-salt foods to ensure that consumers will like (or even prefer) these reformulated food products (Herbert, Bertenshaw, Zandstra, \& Brunstrom, 2014; Liem, Toraman Aydin, \& Zandstra, 2012; Willems, van Hout, Zijlstra, \& Zandstra, 2014).

There is surprisingly little known about consumers" taste perception and liking of reduced-salt foods. Malherbe, Walsh, \& van der Merwe (2003) reported that it is possible to reduce the sodium content of home-prepared composite dishes by about $30 \%$ without significantly changing acceptability. Another study on beef patties showed that, in Ireland and the United Kingdom, the patty with $50 \%$ less salt than the commercially available patties was preferred (Tobin, O"Sullivan, Hamill, \& Kerry, 2012). In contrast, Mitchell, Brunton, \& Wilkinson (2009) and Wang, Lee, \& Lee (2014) showed that reduced-salt foods may be disliked initially. The current challenge 
lies in getting consumers to consume salt-reduced products repeatedly as a few studies have shown that liking for reduced-salt products can be increased when salt is gradually in small steps reduced over time (Bertino, Beauchamp, \& Engelman 1982; Blais et al., 1986; Bobowski, Rendahl, \& Vickers 2015; Bolhuis et al., 2011; Mattes, 1997). In these studies participants shifted their optimal preferred salt level towards lower salt concentrations over 8 to 16 weeks. The relationship between liking and salt intensity is described as a curve in which a certain salt concentration in food is preferred, and higher and lower concentrations are liked less (de Graaf, van Staveren, \& Burema, 1996; Drewnowski, Henderson, Driscoll, \& Rolls, 1996; Zandstra, De Graaf, Mela, \& Van Staveren, 2000). This curve is different for each individual and is among others based on prior food experience and customary use of salt and salty products in the diet (Mattes, 1997; Sullivan \& Birch, 1990; TuorilaOllikainen, Salovaara, \& Kurkela, 1986; Zandstra et al., 2000). Ultimately, it is important to shift this curve to lower salt concentrations and the above-mentioned studies indicate that it is possible to "learn" to prefer products with lower salt concentrations.

A concern with the new South African regulations is that large reductions in salt levels in commercial food may not be effective as consumers may increase their discretionary salt use to compensate for a loss in taste.

The current study is the first consumer study in South Africa to investigate consumer behaviour, attitudes and perceptions towards salt reduction in light of the country"s new salt reduction regulations. More specifically, we assessed liking, perceived salt taste intensity and use of table salt for reduced-salt chicken stew meals. We hypothesized that liking and perceived salt taste intensity would decrease with increased reductions in salt, whereas use of table salt, while consuming the meal, would increase with larger reductions of salt.

\section{Materials and Methods}

\section{Participants}

A group of 432 urban black South African consumers in the Tshwane metropolitan area were recruited by an independent market research agency to participate in the study. Consumers (only one per household) were included if they: 1) had not participated in any market research involving the tasting of food products in the past three months; 2) were regular consumers of chicken stew, i.e. at least twice a month; 3) available and willing to participate in the evaluation on the specific days; 4) not following a restricted diet and/or suffering from any type of food allergy; 5) between 
18 and 65 years old and; 6 ) had an average gross household monthly income of R6 000-R16000 average monthly household income in South Africa at the time R9 364 (South African Audience Research Foundation, 2013). Consumers were not fully informed about the actual purpose of the study (i.e. assessing discretionary salt use) but were told beforehand that the activity consisted of tasting and eating a chicken stew meal at a central venue. Participants were briefed on the procedures and verbal informed consent was obtained prior to participation. At the end of the session, consumers had the opportunity to give written consent as to whether or not their answers could be included in the data set. Participants received a store voucher of R150. Ethical approval for the study was obtained from the Faculty of Natural and Agricultural Science of the University of Pretoria (application EC 140606-053).

\section{Food product}

A meal consisting of chicken stew with rice for lunch/dinner was used. Stock cube powders varying in sodium ( $\mathrm{Na}$ ) content (Table 1 ) were used to prepare four different chicken stews: 1) no salt reduction - $2013 \mathrm{Na}$ level; regular salt level as currently available on the South African market (24473 mg Na/100g), 2) salt reduction lower than 2016 level, i.e. 10\%-reduced (22025 mg Na/100g), 3) 2016 salt level, as per regulatory prescriptions (18000 mg Na/100g), 4) 2019 salt level, as per regulatory prescriptions (13000 mg Na/100g). Subjects were randomly assigned to four groups to eat a full portion of one of the four chicken stews once.

Representative samples of the stock cube powders (in triplicate), and homogenized edible portions of prepared chicken stews (chicken bone removed) (eight samples per treatment) and rice (four replicates) were analysed for elemental $\mathrm{Na}$ content with AA flame atomic absorption spectroscopy (Giron, 1973). These results are shown in Table 1.

\section{Procedure}

The participants were invited to a lunch or early evening meal in a dining room setting at the University of Pretoria, Hatfield campus. The venue accommodated a maximum of 13 consumers at a time, seated at individual tables. On the day, subjects could eat their usual breakfast (and lunch in the case of evening sessions) at home/work and were allowed to drink coffee or tea and to eat a snack at 10:00/14:00 (depending on the session). All subjects were asked not to eat or drink anything else until the tasting session. Upon arrival, trained interviewers greeted and invited individual participants to join them at a table. During the meal one-on-one structured interviews were conducted with the participants in their language of 
Table 1: $\quad$ Sodium (Na) and salt content of stock powders, chicken stews and full meals and effect of salt addition at the table on total salt intake per chicken stew meal

\begin{tabular}{|c|c|c|c|c|c|}
\hline & Unit & $\begin{array}{c}\text { Group } 1 \\
2013 \\
\text { Na level }\end{array}$ & $\begin{array}{c}\text { Group } 2 \\
2013-10 \% \\
\text { Na level }\end{array}$ & $\begin{array}{l}\text { Group } 3 \\
2016 \\
\text { Na level }\end{array}$ & $\begin{array}{c}\text { Group } 4 \\
2019 \\
\text { Na level }\end{array}$ \\
\hline \multicolumn{6}{|c|}{$\mathrm{Na}$ and salt content of stock cubes, chicken stew and per full meal serving } \\
\hline Na reduction: stock powders & $\%$ & - & -10 & -26 & -47 \\
\hline $\begin{array}{l}\mathrm{Na} \text { in chicken stew* (as } \\
\text { prepared }\end{array}$ & $\mathrm{mg} / 100 \mathrm{~g}$ & $498( \pm 31)$ & $467( \pm 41)$ & $401( \pm 30)$ & $328( \pm 28)$ \\
\hline Na reduction: chicken stew & $\%$ & - & -6 & -19 & -34 \\
\hline Na content of meal serving\# & $\mathrm{mg}$ & 906 & 866 & 781 & 687 \\
\hline Na reduction: meal & $\%$ & - & -4 & -14 & -24 \\
\hline Salt content per meal serving & g & $\begin{array}{c}2,266 \\
\text { (benchmark) }\end{array}$ & 2,166 & 1,953 & 1,718 \\
\hline $\begin{array}{l}\text { Change in salt content per } \\
\text { serving compared to stew } \\
\text { with } 2013 \mathrm{Na} \text { level }\end{array}$ & $\%$ & - & -4 & -14 & -24 \\
\hline \multicolumn{6}{|c|}{ Effect of salt addition at the table: including all participants $(n=432)$} \\
\hline $\begin{array}{l}\text { Total amount of salt } \\
\text { consumed as part of full } \\
\text { meal (including table salt } \\
\text { use) }\end{array}$ & g & 2,299 & 2,230 & 2,059 & 1,843 \\
\hline $\begin{array}{l}\text { Change in salt consumed as } \\
\text { part of meal compared to } \\
\text { group } 1\end{array}$ & $\%$ & - & -3 & -10 & -20 \\
\hline $\begin{array}{l}\text { Change in salt consumed as } \\
\text { part of meal and salt content } \\
\text { in meal as served }\end{array}$ & $\%$ & 1 & 3 & 5 & 7 \\
\hline $\begin{array}{l}\text { Change in salt consumed as } \\
\text { part of meal and benchmark } \\
\text { meal with } 2013 \mathrm{Na} \text { level }\end{array}$ & $\%$ & 1 & -2 & -9 & -19 \\
\hline \multicolumn{6}{|c|}{ Effect of salt addition at the table: including only those participants that added salt at the table $(n=82)$} \\
\hline $\begin{array}{l}\text { Total amount of salt } \\
\text { consumed as part of full } \\
\text { meal (including table salt } \\
\text { use) }\end{array}$ & g & 2,495 & 2,497 & 2,486 & 2,171 \\
\hline $\begin{array}{l}\text { Change in salt consumed as } \\
\text { part of meal compared to } \\
\text { group } 1\end{array}$ & $\%$ & - & 0 & -4 & -10 \\
\hline $\begin{array}{l}\text { Change in salt consumed as } \\
\text { part of meal and salt content } \\
\text { in meal as served }\end{array}$ & $\%$ & 10 & 15 & 23 & 26 \\
\hline $\begin{array}{l}\text { Change in salt consumed as } \\
\text { part of meal and benchmark } \\
\text { meal with } 2013 \mathrm{Na} \text { level }\end{array}$ & $\%$ & 10 & 10 & 10 & -4 \\
\hline
\end{tabular}

\footnotetext{
*Edible portion excludes chicken drumstick bone
}

\# Na content of cooked rice $(\mathrm{mg} / 100 \mathrm{~g}$ on wet base) $=264$ ( \pm 81); Meal serving $=364 \mathrm{~g} \pm 25 \mathrm{~g}$ ( $\sim 100 \mathrm{~g}$ rice: $164 \mathrm{~g}$ stew including bone $\sim 35 \mathrm{~g}$ ); A serving of chicken stew without bone $=\sim 129 \mathrm{~g}$

choice. Participants were asked to consume a full portion of the chicken stew (the stew included vegetables), together with rice. A popular local radio station was 
playing in the background to facilitate a more natural setting. The decision to interview each participant individually was taken to allow the respondents to focus on consuming and evaluating the meal and not on the completion of a rather complex questionnaire with the option of question branching based on responses given.

\section{Assessments}

Actual food intake was measured by weighing quantities served and leftovers. The time taken to consume the meal and discretionary usage of salt and pepper from shakers on the table was measured as well.

Before consuming the meal, consumers were asked some demographic information (not part of this paper) and: "How hungry are you at this moment?" The meal was served and consumers were then asked: "When you look at this meal, how much do you want to eat this meal right now?" and "When you look at this meal, how much do you think will you like or dislike eating it?". Participants were then instructed to taste the product and after one minute they were asked to indicate "How much they liked or disliked... the meal?,...the chicken?,...the vegetables?,... the rice? and ...the sauce?". The consumers could then eat as much of the meal as they wanted and at the end they were again asked to indicate "How much they liked or disliked the meal?". All questions were answered using 9-point scales.

A set of salt and pepper shakers were available at each individual table setting. Participants were free to add salt and/or pepper if they wished. Unknown to the participants, the salt-shakers and pepper-shakers were weighed on a digital scale with microgram accuracy before and after participants consumed the meal.

At the end of the meal, some extra questions regarding salt awareness, attitudes and beliefs towards salt were asked:

- "How often do you add salt to food before you have tasted it?"

- "In the food you eat at home: is salt added during cooking?"

- $\quad$ "Compared to other people, how much salt do you think you add to meals ...

at the table whilst eating? ... during food preparation?"

The consumers were also asked to indicate on a 9-point scale "When thinking about the meal that you consumed today and using the scale, how did you find the saltiness of the meal?"

A series of questions was then asked to assess consumers" interest in lowering salt in their diet. Subjects were divided into five categories based on the Trans Theoretical Model of Behavioural Change (Prochaska, DiClemente, \& Norcross, 1992), i.e. from "no interest and no action" (stage 1) up to "interest and 
repeated action" (stage 5) as applied previously by Newson et al., (2013) in an online salt usage survey. Note, however, that there were some differences in the way that the questions were phrased as noted below.

"Are you interested or not interested in lowering salt (sodium) in your diet?"

Considering only the respondents that were interested in lowering salt (sodium) in their diet,

"Have you already started lowering salt (sodium) in your diet?"

Considering only the respondents that have started to lower salt (sodium) in their diet, "When did you start?"
Considering only the respondents that are interested in lowering salt (sodium) in their diet but have not already started, "Do you intend to start lowering salt (sodium) in your diet?" Considering only the respondents that intend to start lowering salt (sodium) in the diet, "When do you intent to start?"

Using show cards with answer options, consumers were also asked: "Where do you think most of the salt in your diet comes from?", "Whether or not checking labels on food products to check the salt content is something that...I do frequently? ...l do without thinking, ...belongs to my daily routine,...is typically me?...I have been doing for a long time". Consumers responded to the statement "If a teaspoon is 5 grams, how many grams of salt do you think you currently consume in one day?" and a question using a just about right scale (JAR) "How much salt do you think you consume?"

\section{Statistical analysis}

Results of questions requesting ratings of hunger, liking of meal and meal components, salt perception of meal, time taken to eat meal, quantities consumed and left over were analysed by one way analysis of variance (ANOVA) with meal type as independent variable. Where appropriate, additional two-way ANOVA"s were performed (i.e. to test the effects of meal type served and salt/pepper usage on quantities of salt/pepper used/liking of meals). Pearson correlation analyses were used to relate liking of the meal after 1 min with liking at the end of the meal, and the percentage of food consumed and the left overs. Least square means were further analysed using the least significant difference (LSD) test. XLStat Version 2008.7.03 (Addinsoft) was used for data analysis. Statistical significance was set at $p<0.05$, and data are provided as mean plus and minus the standard deviation. Descriptive statistics and where suitable, frequency and contingency tables of answers to 
demographic and background information questions, attitudes and behaviour, were compiled.

\section{Results}

A total of 432 consumers [aged 35.2 years \pm 12.3 years; $49 \%$ male and $51 \%$ female) participated in the study.

\section{Action stage of salt reduction of the study population}

Figure 1 shows the stages of behavioural change for salt reduction for the consumers in this study. Thirty seven $\%$ of the consumers had no interest in changing their salt intake [comparable to stage 1 of Prochaska et al., (1992)], while 12\% were interested in starting to lower their intake (comparable to stage 2 and 3). A third (32\%) of the consumers reported that they had already started to reduce salt intake more than six months earlier (comparable with stage 5), while 19\% had already done so during the last six months (comparable with stage 4). Consumers in the different stages of change were similarly distributed in the groups that consumed a particular chicken stew meal $\left(x^{2}=16.1, d f=12, p=0.187\right)$.

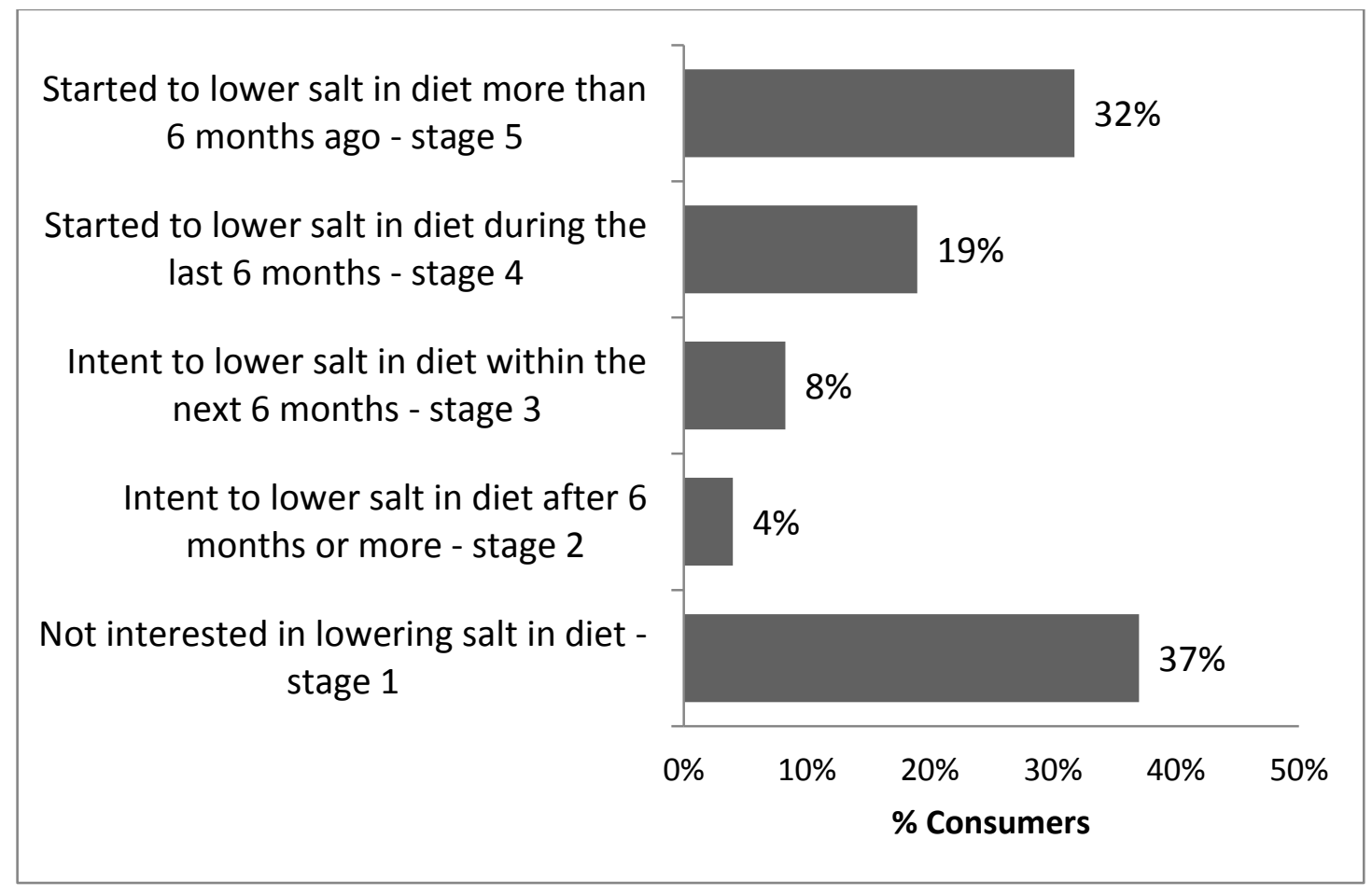

Figure 1: $\quad$ Distribution of the stages of change (based on Prochaska et al., 1992) with regards to lowering salt in the diet for the South African consumers that participated in this study 
Table 2: $\quad$ Effect of Na content of chicken stew meal on liking of meal and meal components (mean \pm SD), perception of saltiness (mean \pm $S D$ ) and meal duration (average minutes $\pm S D$ )

\begin{tabular}{|c|c|c|c|c|c|c|c|c|}
\hline \multicolumn{3}{|c|}{ Questions } & \multicolumn{4}{|c|}{ Chicken stew meals } & \multirow[t]{3}{*}{$p$-value } & \multirow[t]{3}{*}{ F-value } \\
\hline & & & \multirow{2}{*}{$\begin{array}{l}2013 \\
\text { Na level }\end{array}$} & \multirow{2}{*}{$\begin{array}{l}2013-10 \% \\
\text { Na level }\end{array}$} & \multirow{2}{*}{$\begin{array}{l}2016 \\
\text { Na level }\end{array}$} & \multirow{2}{*}{$\begin{array}{l}2019 \\
\text { Na level }\end{array}$} & & \\
\hline & & & & & & & & \\
\hline \multirow[t]{3}{*}{ Pre-meal } & How hungry do you feel at this moment?* & $\begin{array}{l}1=\text { Not hungry at all } \\
9=\text { Very hungry }\end{array}$ & $5.9 \pm 1.9$ & $5.6 \pm 2.1$ & $5.6 \pm 2.1$ & $5.7 \pm 2.0$ & 0.65 & 0.55 \\
\hline & $\begin{array}{l}\text { When you look at this meal, how much do } \\
\text { you want to eat this meal right now? }\end{array}$ & $\begin{array}{l}1=\text { Not at all } \\
9=\text { Very much }\end{array}$ & $6.8 \pm 1.9$ & $6.9 \pm 2.0$ & $6.9 \pm 1.9$ & $6.9 \pm 1.8$ & 0.95 & 0.12 \\
\hline & $\begin{array}{l}\text { When you look at this meal, how much do } \\
\text { you think will you like or dislike eating it? }\end{array}$ & $\begin{array}{l}\text { 1=Dislike very much } \\
\text { 9=Like very much }\end{array}$ & $7.2 \pm 1.8$ & $7.4 \pm 1.8$ & $7.5 \pm 1.7$ & $7.1 \pm 1.8$ & 0.56 & 0.68 \\
\hline \multirow{5}{*}{$\begin{array}{l}1 \text { min after } \\
\text { start of meal }\end{array}$} & Liking of meal & \multirow{5}{*}{$\begin{array}{l}\text { 1=Dislike very much } \\
\text { 9=Like very much }\end{array}$} & $7.6 \pm 1.6$ & $7.8 \pm 1.5$ & $7.9 \pm 1.3$ & $7.5 \pm 1.6$ & 0.12 & 1.95 \\
\hline & Liking of chicken & & $7.4 \pm 2.0$ & $7.6 \pm 1.8$ & $7.6 \pm 1.5$ & $7.4 \pm 1.9$ & 0.87 & 0.25 \\
\hline & Liking of rice & & $7.2 \pm 1.9$ & $7.1 \pm 1.8$ & $7.6 \pm 1.7$ & $7.5 \pm 1.7$ & 0.16 & 1.75 \\
\hline & Liking of vegetables & & $7.8 \pm 1.6$ & $7.7 \pm 1.6$ & $7.8 \pm 1.8$ & $7.5 \pm 1.9$ & 0.48 & 0.83 \\
\hline & Liking of soup (sauce) & & $7.6 \pm 1.7$ & $7.6 \pm 2.0$ & $7.4 \pm 1.9$ & $7.4 \pm 1.7$ & 0.75 & 0.41 \\
\hline \multirow[t]{3}{*}{$\begin{array}{l}\text { After } \\
\text { completion }\end{array}$} & Liking of meal & $\begin{array}{l}\text { 1=Dislike very much } \\
\text { 9=Like very much }\end{array}$ & $7.9 \pm 1.3$ & $8.0 \pm 1.5$ & $8.0 \pm 1.4$ & $7.9 \pm 1.4$ & 0.83 & 0.29 \\
\hline & $\begin{array}{l}\text { Difference in liking ratings of meal after } \\
\text { completion of meal and } 1 \text { min after start of } \\
\text { meal }\end{array}$ & & $0.3 \pm 1.1$ & $0.2 \pm 1.2$ & $0.1 \pm 1.2$ & $0.4 \pm 1.3$ & 0.27 & 1.30 \\
\hline & How did you find the saltiness of the meal? & $\begin{array}{l}1=\text { Not at all salty } \\
9=\text { Very salty }\end{array}$ & $4.6 \pm 1.8$ & $4.4 \pm 1.6$ & $4.4 \pm 1.8$ & $4.3 \pm 1.6$ & 0.72 & 0.45 \\
\hline \multicolumn{3}{|c|}{ Time taken to eat the meal (minutes) } & $7.3 \pm 2.9$ & $8.0 \pm 3.0$ & $7.9 \pm 2.9$ & $7.4 \pm 3.0$ & 0.14 & 1.84 \\
\hline
\end{tabular}




\section{Effect of salt content on liking of meal and meal components}

Table 2 shows the hunger, desire to eat, and liking ratings, just before, during and directly after finishing the chicken stew meals. The pre-meal hunger and desire to eat ratings for the four chicken meals did not differ ( $p>0.05$ ). On average, all chicken stews were equally well-liked with mean scores from 7.5 to 7.9 on 9-point scales. More specifically, there were no differences in liking ratings for the meals at the start, liking ratings while eating as well as liking ratings for the different components of the meal (chicken, rice, vegetables, sauce) among the four groups ( $p>0.05)$. In addition, the time taken to consume the meal and the relative quantity of meal eaten (average $290.3 \pm 70.6 \mathrm{~g}$; df $=3, \mathrm{~F}=1.34, \mathrm{p}=0.26$ ) or left over (average $74.0 \pm 68.8 \mathrm{~g}$; $\mathrm{df}=3$, $F=1.07, p=0.36$ ) was not influenced by the salt content of the meals served. Similarly, the salt content of the chicken stew did not influence the differences in the liking ratings at the start compared to liking ratings at the end of the meal. . Liking ratings after the first bite of the meal were positively correlated $\left(R^{2}=44 \%\right)$ with liking ratings at the end of the meal, and significantly $(p<0.05)$ although weakly negatively correlated $\left(R^{2}=9 \%\right)$ with the percentage of food not consumed and left on the plate. When prompted about the saltiness of the meal after consumption, average ratings for the meals with different $\mathrm{Na}$ levels were not significantly different ( $\mathrm{df}=3, \mathrm{~F}=0.45$, $\mathrm{p}=0.72)$.

\section{Salt/pepper consumption as part of meal}

Overall, $81 \%$ of participants did not add salt and $82 \%$ did not add pepper to the chicken stews (Error! Reference source not found.). Including all the participants, the average amount of table salt added increased $(\mathrm{df}=3, \mathrm{~F}=3.4, \mathrm{p}=0.02)$ as the salt content of the chicken stews decreased from the $2013 \mathrm{Na}$ level $(0.03 \pm 0.11 \mathrm{~g})$, to the $2013-10 \% \mathrm{Na}$ level $(0.06 \pm 0.17 \mathrm{~g})$, to the $2016 \mathrm{Na}$ level $(0.11 \pm 0.33 \mathrm{~g})$ and to the $2019 \mathrm{Na}$ level $(0.13$ $\pm 0.26 \mathrm{~g}$ ). The percentage of consumers who added salt back at the table also increased across the four chicken meals from $12 \%$ for the $2013 \mathrm{Na}$ level up to $27 \%$ for the $2019 \mathrm{Na}$ level chicken stews. When comparing the salt content of the meals as served with the total salt consumed (i.e. salt content in meal plus added table salt) across the groups, consumers added more salt back to their meals respectively $1 \%, 3 \%, 5 \%$ and $7 \%$ as the salt content of the chicken stews decreased. However, when comparing the total salt consumed (i.e. salt content in meals plus added table salt) to the benchmark $2013 \mathrm{Na}$ level chicken stew meal as served, the net effect for the total group was a gradual reduction in overall salt intake of $2 \%, 9 \%$ and $19 \%$ for the $2013-10 \% \mathrm{Na}$ level, $2016 \mathrm{Na}$ level and $2019 \mathrm{Na}$ level chicken stews respectively (Table 1), despite the increased table salt usage. 
Including only those consumers that added salt back at the table (Table 1 and Figure 2), the average amount of table salt added back significantly increased from the $2013 \mathrm{Na}$ level $(0.23 \pm 0.21 \mathrm{~g})$, to the $2013-10 \% \mathrm{Na}$ level $(0.33 \pm 0.24 \mathrm{~g})$, to the 2016 Na level $(0.54 \pm 0.59 \mathrm{~g})$ and to the $2019 \mathrm{Na}$ level $(0.45 \pm 0.31 \mathrm{~g})(\mathrm{df}=3, \mathrm{~F}=8.85$, $p<0.001)$. When comparing the salt content of the chicken stew meals as served with the total salt intake consumed (i.e. salt content in chicken stews plus added table salt) within the groups, consumers gradually added more salt back $10 \%, 15 \%, 27 \%$ and $26 \%$ as the salt content of the chicken stews decreased. Moreover, when comparing the total salt intake consumed (i.e. salt content in chicken stew meals plus added table salt) to the benchmark $2013 \mathrm{Na}$ level chicken stew as served, the net effect for these participants was an overcompensation of $10 \%$ for the $2013 \mathrm{Na}$ level, $15 \%$ for the $2013-10 \% \mathrm{Na}$ level and $27 \%$ for the $2016 \mathrm{Na}$ level chicken stews (Table 1), whereas there was a $4 \%$ lower salt intake for the $2019 \mathrm{Na}$ level chicken stew. In contrast, the amount of pepper added (Figure 2), was similar across meals ( $p>0.05$ ).

Participants that added salt to the meals liked the stews significantly less than those that did not add salt at the table (mean liking 8.0 vs. 7.6; $F=4.58, p=0.03$ ). However, no significant interaction effect of salt usage during meal and liking for the different stew types was found. With respect to liking ratings for the chicken stew meals, consumers with an interest in lowering the salt in their diet gave similar liking ratings compared to those that did not indicate an interest to lower salt in the diet $(F=0.76$, $\mathrm{p}=0.47)$.

\section{Awareness of salt in the diet and in food products}

Only $13 \%$ of participants were of the opinion that salt in the foods that they purchased is the most significant source of salt in their diet (Table 3 ). Sixty five $\%$ of consumers indicated that the addition of salt during cooking or at the table was the main contributing factor for salt intake. Sixty five \% of consumers also indicated that they do not check labels of food products for salt content. Twenty five \% of consumers reported that they thought they consumed more than $5 \mathrm{~g}$ of salt per day. Fifty two \% of participants indicated that their salt intake is just the right amount whilst the rest considered that they used either too much (15\%) or too little salt (33\%) (Table 3$)$. 


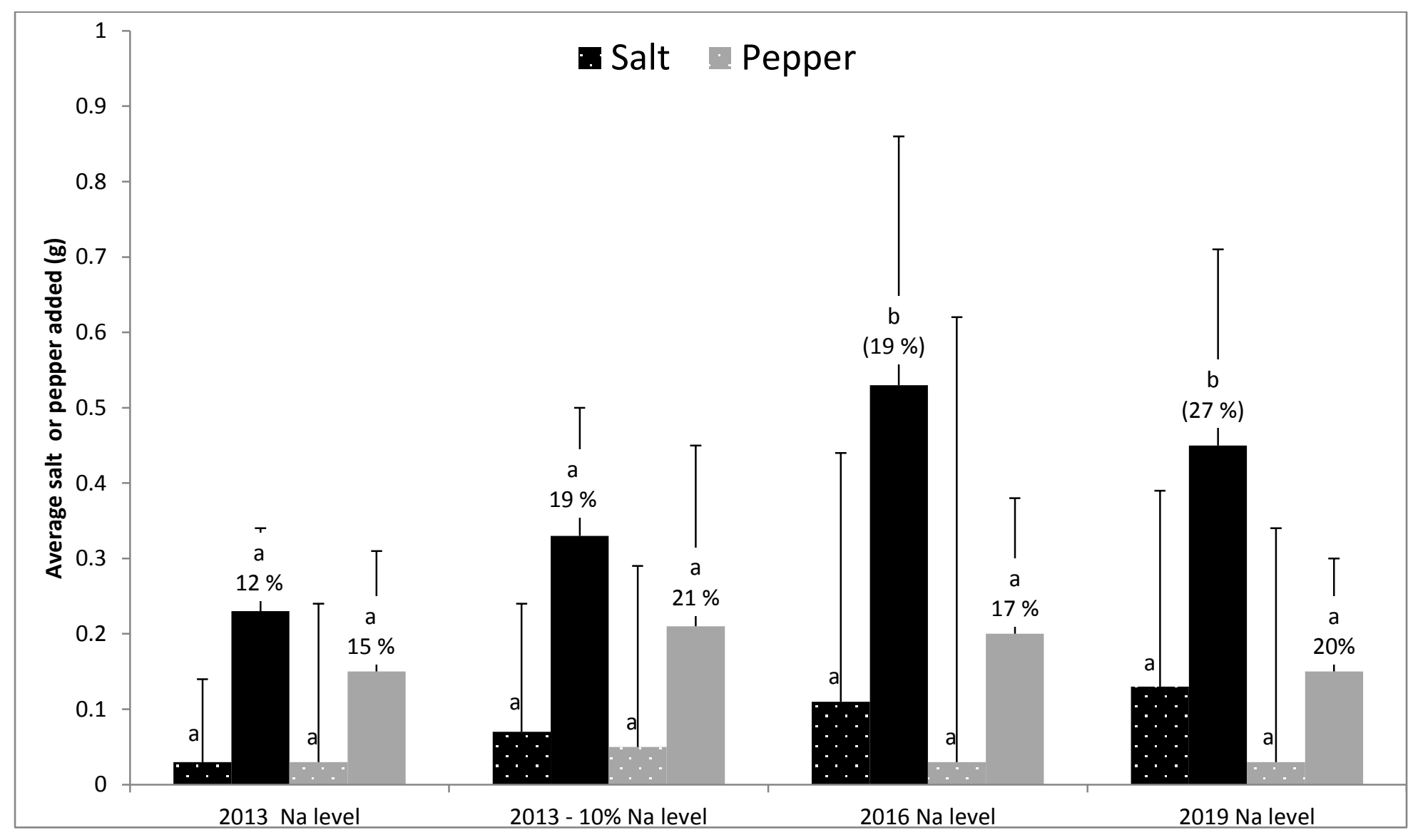

Figure 2: $\quad$ Average quantities $(g \pm S D$ ) of salt (dark bars) and pepper (light bars) added to the chicken stew meals with different sodium levels for the total group per meal (dotted bars) and for those consumers that added salt and/or pepper, respectively (solid bars with percentages of participants that added salt/pepper in brackets).

${ }^{\mathrm{ab}}$ Average values for a subgroup (same style of bars) with different letters, differed significantly $(p<0.05)$. 
Table 3: $\quad$ Characteristics and behaviours of consumers $(n=432)$ concerning salt reduction

\begin{tabular}{lc}
\hline & $\%$ \\
\hline Where do you think does most of the salt in your diet come from? & \\
Salt added during cooking & 43 \\
Salt added while eating (e.g. salting food at the table) & 22 \\
The salt that is in foods which you purchase & 13 \\
Salt from foods that you eat in restaurants/ take away meals & 23 \\
\hline Checking labels of food products to check the salt content is \\
something that ...: \\
I do frequently & 39 \\
I do without thinking & 37 \\
belongs to my daily routine & 39 \\
is typically me & 45 \\
I have been doing for a long time & 44 \\
\hline How much salt do you think you consume? & 4 \\
Far too much & 11 \\
Too much & 52 \\
Just the right amount & 26 \\
Too little & 7 \\
Far too little & \\
\hline If a teaspoon of salt is 5 grams, how many grams of salt do you \\
think you consume in one day? \\
\% Consumers that reported more than $5 \mathrm{~g}$ (maximum 60g) \\
\% Consumers that reported $5 \mathrm{~g}$ \\
\% Consumers that reported less than $5 \mathrm{~g}$ \\
\% Consumers that did not know or did not respond & 25 \\
\hline
\end{tabular}

\section{Discussion \& Conclusions}

This is the first study to investigate the impact of replacing stock cube powders with a reduced salt variant in a popular, savoury meal on behaviours related to the use of table salt and acceptability of the meal. The extent of salt reduction was based on the levels identified in South Africa's new salt regulations that will come into effect in 2016 and 2019. Chicken stews that had been prepared with salt-reduced stock cube powders were equally well-liked by South African consumers as a recipe made with stock cube powder with the current salt content (24473mg Na/100g). Moreover, a gradual reduction of the salt in the chicken stews resulted in a reduced salt intake of up to $19 \%$ for the total group compared to the benchmark $2013 \mathrm{Na}$ level chicken meal. However, almost a fifth (19\%) of consumers compensated for salt reduction by adding salt back at the table to their chicken meals. This group added increased amounts of salt with increased reductions in salt content of the chicken meals, even to the point of full compensation. This research provides new insights on consumers" table salt use behaviour and emphasises the need for consumer-focused behaviour change approaches, in addition to reformulation of products. 
Salt is commonly used to enhance the general flavour of a food and to interact with other flavour elements, e.g. by reducing bitterness (Breslin \& Beauchamp, 1997; Busch, Feunekes, \& Hauer, 2010). The challenge is to reduce salt while maintaining the good taste of the original product to ensure consumer liking and enjoyment (Willems et al., 2014; Zandstra et al., 2000). In our study, we expected that the reduced-salt chicken stews would be less liked than the regularsalt chicken stew: the salt was removed from the stock cube powders and not replaced by other salts or adjusted for in the recipe. In contrast to expectations, the chicken stews scored highly on liking throughout the consumption of the meal irrespective of the salt reduction. In an earlier study with soup, a $15 \%$ salt reduction was acceptable, whereas a $30 \%$ salt reduction was perceived as "not salty enough" (Liem, Miremadi, Zandstra, \& Keast, 2012), while another study reported that a reduction of up to $48 \%$ was acceptable when compensated for with flavourings such as rosemary (Michelle Mitchell, Brunton, \& Wilkinson, 2013). In addition, based on earlier sensory-specific satiety research, it was expected that liking would decrease over consumption within a meal moment (Rolls, Rolls, Rowe, \& Sweeney, 1981). However, this did not happen and liking ratings at the end of the meal tended to be even slightly higher than at the start of the meal. The different components of the meal (i.e. chicken, vegetables, rice and sauce) may have counterbalanced the sensory-specific satiety effect observed when compared to more simple meals such as a bouillon soup.

One risk of introducing lower salt products without good consumer awareness is that consumers may add salt back at the table, thereby reducing the impact of the lower salt products. A key question is therefore whether people compensate for lower salt content by adding it back via a table salt shaker. In our study, $81 \%$ of participants did not add table salt to the meals whereas $19 \%$ did. Furthermore, those that added salt to the meals liked the meals significantly less than participants who did not add salt. Previously, it has been shown that people do not fully compensate via a salt shaker when their total diet was reduced in salt. For example, in one study, participants received a clinically prepared diet that was significantly reduced in salt over a 13-week period, whilst allowing them unlimited use of a salt shaker to salt their foods to their taste. Interestingly, compensation (replacement of the salt removed from the diet by salt added at the table) was less than $20 \%$ (Beauchamp, Bertino, \& Engelman, 1987). However, a recent study found to the contrary. When a single food product, soup, was reduced in salt: participants were much more likely to add salt even to the point of over compensating (Liem et al., 2012b). In line with this, our study, which did not include salt labeling or nutrition education, showed that more 
participants added table salt when salt was reduced in a chicken stew meal. Although these studies still need to be replicated in a home-use setting, they seem to indicate that a significant number of consumers are likely to add extra salt at the table, even to the point of compensation, if the salt content of products is reduced.

National salt campaigns can increase consumer awareness and make a noticeable impact on salt intake at the population level. For example, following a national campaign in the United Kingdom, self-report data indicated that the number of people adding salt to food at the table fell by almost $10 \%$ in the subsequent five years (Sutherland et al., 2013). A South African national campaign promoting salt reduction in diets, Salt Watch was launched in 2014 (www.saltwatch.co.za). It has been shown that an education programme improves the adherence to a low-sodium diet in heart failure patients (Welsh et al., 2013). Further research into the impacts of nutrition communication and education about salt reduction on salt taste perception and the compensatory use of table salt is needed.

In order to reduce the salt content of food products in a manner acceptable to consumers and which also does not result in compensatory use of discretionary salt, it is vital that we achieve a better understanding of the nature of liking of the taste of salt and how this liking can be influenced (Lampuré et al., 2015; Zandstra et al., 2015). It is important to take small steps in salt reduction and ensure products remain accepted by consumers over repeated consumption (Busch et al., 2010). Repeated consumption of a reduced salt product could positively affect the acceptability of the product. In a study using a repeated consumption design, the groups receiving the no added salt soup showed an increased liking for this soup from the third consumption and also an increased perceived saltiness of all soups as a function of consumption (Methven, Langreney, \& Prescott, 2012). An Australian study (Girgis et al., 2003) demonstrated that the salt content of bread can be gradually reduced by up to $25 \%$ over a six week period while maintaining consumer acceptability. Another interesting approach could be to implement a spices and herbs behavioural intervention as conducted by Anderson et al., (2014). This intervention included advice on replacing sodium with spices and herbs as a way to facilitate adherence to dietary sodium recommendations, and it resulted in a strong reduction in salt intake after a time period of 20 weeks. In addition, reduction of table salt use may also be achieved by reducing the size of holes in salt shakers as there are indications of a strong role for habit in table salt use. For example, a study showed that twice as much salt was used with large, compared to small holed salt shakers and, importantly, this effect appeared to remain over time (Farleigh, Shepherd, \& Wharf, 1990). 
There are some limitations of the research that should be mentioned. The meals were evaluated at a central location and each participant was interviewed individually by an interviewer in order for the participant to focus on the activity of consuming a meal and not on completing a questionnaire. It is possible that the presence of an interviewer during the meal could have resulted in socially desirable responses, i.e. higher liking scores and lowered use of table salt and pepper. Also, we used a parallel design in which participants received only one meal with different levels of salt reduction. For future studies we recommend a cross-over design in which participants are assigned to each of the four meals in random order and thus can serve as their own control. Finally, the question remains how best to implement these results. The results were found for one specific product, i.e. chicken stew in one country, i.e. South Africa. From unpublished internal data the authors are aware that salt reduction possibilities depend very much on product type (i.e. we expect a higher impact on liking of single component meals (e.g. bouillon soup, meat) than composite multi-component meals (e.g. chicken stews), usage, consumers" interest and awareness around salt reduction, and all need a different approach. To meet South Africa"s new salt regulations, further reductions in the salt content in foods are required while maintaining good taste and consumer liking, as well as a change in attitudes and behaviour amongst consumers. Thus we recommended that these findings be replicated using a broader range of products with consumers in South Africa.

Consumer research in South Africa showed that chicken stew meals prepared with salt-reduced stock powders that comply with 2016 and 2019 regulation levels, were equally well liked by South African consumers as chicken stews with $2013 \mathrm{Na}$ levels. In addition to reducing salt in products, consumer behaviour change is required in order to drive the desired choice behaviour and minimize counter-active table salt use.

\section{Acknowledgements}

Research assistance of Marise Kinnear (University of Pretoria), Bianca Swanepoel (North-West University), Stacey Grant, Lisa Wiegand, Elizabeth Macgregor, Karen Van Tonder, Sharon Chinasamy and Robert Gunn (Unilever South Africa) is kindly acknowledged. 


\section{References}

Anderson, C., Cobb, L., Miller, E., Woodward, M., Chang, A., Mongraw-Chaffin, M., \& Appel, L. (2014). Effects of a behavioural intervention that emphasizes spices and herbs on adherence to recommended sodium intake. American Heart Association, Report MP37.

Barlow, R., Connell, M., \& Levendig, B. (1982). A comparative study of urinary sodium and potassium excretion in normotensive urban black and white South African males. South African Medical Journal, 62, 939-941.

Beauchamp, G. K., Bertino, M., \& Engelman, K. (1987). Failure to compensate decreased dietary sodium with increased table salt usage. Journal of the American Medical Association, 258(22), 3275-3278.

Bertino, M., Beauchamp, G. K., \& Engelman, K. (1982). Long-term reduction in dietary sodium alters the taste of salt. American Journal of Clinical Nutrition, 36(6), 1134-1144.

Bertram, M. Y., Steyn, K., Wentzel-Viljoen, E., Tollman, S., \& Hofman, K. J. (2012). Reducing the sodium content of high-salt foods: Effect on cardiovascular disease in South Africa. South African Medical Journal, 102(9), 743-745. doi:10.7196/samj.5832

Bibbins-Domingo, K., Chertow, G. M., Coxson, P. G., Moran, A., Lightwood, J. M., Pletcher, M. J., \& Goldman, L. (2010). Projected effect of dietary salt reductions on future cardiovascular disease. The New England Journal of Medicine, 362(7), 590-9. doi:10.1056/NEJMoa0907355

Blais, C. A., Pangborn, R. M., Borhani, N. O., Ferrell, M. F., Prineas, R. J., \& Laing, B. (1986). Effect of dietary sodium restriction on taste responses to sodium chloride: A longitudinal study. American Journal of Clinical Nutrition, 44(2), 232243.

Bobowski, N., Rendahl, A., \& Vickers, Z. (2015). A longitudinal comparison of two salt reduction strategies: Acceptability of a low sodium food depends on the consumer. Food Quality and Preference, 40, 270-278.

doi:10.1016/j.foodqual.2014.07.019

Bolhuis, D. P., Temme, E. H. M., Koeman, F. T., Noort, M. W. J., Kremer, S., \& Janssen, A. M. (2011). A salt reduction of $50 \%$ in bread does not decrease bread consumption or increase sodium intake by the choice of sandwich fillings. The Journal of Nutrition, 141(12), 2249-55. doi:10.3945/jn.111.141366

Breslin, P. A. S., \& Beauchamp, G. K. (1997). Salt enhances flavour by suppressing bitterness [5]. Nature, 387, 563-563.

Brown, I. J., Tzoulaki, I., Candeias, V., \& Elliott, P. (2009). Salt intakes around the world: implications for public health. International Journal of Epidemiology, 38(3), 791-813. doi:10.1093/ije/dyp139

Busch, J., Feunekes, G., \& Hauer, B. (2010). Salt reduction and the consumer perspective. New Food Magazine, 2, 36-39. 
Charlton, K. E., Steyn, K., Levitt, N. S., Zulu, J. V, Jonathan, D., Veldman, F. J., \& Nel, J. H. (2005). Diet and blood pressure in South Africa: Intake of foods containing sodium, potassium, calcium, and magnesium in three ethnic groups. Nutrition, 21(1), 39-50. doi:10.1016/j.nut.2004.09.007

Cook, N. R., Appel, L. J., \& Whelton, P. K. (2014). Lower levels of sodium intake and reduced cardiovascular risk. Circulation, 129(9), 981-9. doi:10.1161/CIRCULATIONAHA.113.006032

De Graaf, C., van Staveren, W., \& Burema, J. (1996). Psychophysical and Psychohedonic Functions of Four Common Food Flavours in Elderly Subjects. Chemical Senses, 21(3), 293-302. doi:10.1093/chemse/21.3.293

Department of Health. Regulations relating to the reduction of sodium in certain foodstuffs and related matters. R214. (2013). South Africa. Retrieved from www.info.gov.za/view/DownloadFileAction?id=186474.

Dötsch, M., Busch, J., Batenburg, M., Liem, G., Tareilus, E., Mueller, R., \& Meijer, G. (2009). Strategies to reduce sodium consumption: a food industry perspective. Critical Reviews in Food Science and Nutrition, 49(10), 841-51. doi:10.1080/10408390903044297

Drewnowski, A., Henderson, S. A., Driscoll, A., \& Rolls, B. J. (1996). Salt taste perceptions and preferences are unrelated to sodium consumption in healthy older adults. Journal of the American Dietetic Association, 96(5), 471-4. doi:10.1016/S0002-8223(96)00131-9

Farleigh, C. A., Shepherd, R., \& Wharf, S. G. (1990). The effect of manipulation of salt pot hole size on table salt use. Food Quality and Preference, 2(1), 13-20. doi:10.1016/0950-3293(90)90026-Q

Girgis, S., Neal, B., Prescott, J., Prendergast, J., Dumbrell, S., Turner, C., \& Woodward, M. (2003). A one-quarter reduction in the salt content of bread can be made without detection. European Journal of Clinical Nutrition, 57(4), 61620. doi:10.1038/sj.ejcn.1601583

He, F. J., \& MacGregor, G. A. (2003). How far should salt intake be reduced? Hypertension, 42(6), 1093-9. doi:10.1161/01.HYP.0000102864.05174.E8

He, F. J., \& MacGregor, G. A. (2009). A comprehensive review on salt and health and current experience of worldwide salt reduction programmes. Journal of Human Hypertension, 23(6), 363-84. doi:10.1038/jhh.2008.144

He, F. J., \& MacGregor, G. A. (2010). Reducing population salt intake worldwide: from evidence to implementation. Progress in Cardiovascular Diseases, 52(5), 363-82. doi:10.1016/j.pcad.2009.12.006

Herbert, V., Bertenshaw, E. J., Zandstra, E. H., \& Brunstrom, J. M. (2014). Memory processes in the development of reduced-salt foods. Appetite, 83, 125-34. doi:10.1016/j.appet.2014.08.019 
Hoosen, S., Seedat, Y. K., \& Bhigjee, A. I. (1990). A study of urinary and intracellular sodium and potassium, renin, aldosterone, and hypertension in blacks and Indians in Natal. Cardiovascular Drugs and Therapy, 4(SUPPL. 2), 363-365.

James, W. P. T., Ralph, A., \& Sanchez-Castillo, C. P. (1987). The dominance of salt in manufactured food in the sodium intake of affluent societies. Lancet, 1(8530), 426-429.

Lampuré, A., Schlich, P., Deglaire, A., Castetbon, K., Péneau, S., Hercberg, S. and Méjean, C., 2015. Sociodemographic, psychological, and lifestyle characteristics are associated with a liking for salty and sweet tastes in French adults. Journal of Nutrition, 145(3), 587-594.

Liem, D. G., Miremadi, F., Zandstra, E. H., \& Keast, R. S. J. (2012). Health labelling can influence taste perception and use of table salt for reduced-sodium products. Public Health Nutrition, 15(12), 2340-7. doi:10.1017/S136898001200064X

Liem, D. G., Toraman Aydin, N., \& Zandstra, E. H. (2012). Effects of health labels on expected and actual taste perception of soup. Food Quality and Preference, 25(2), 192-197. doi:10.1016/j.foodqual.2012.02.015

Malherbe, M., Walsh, C., \& van der Merwe, C. (2003). Consumer acceptability and salt perception of food with a reduced sodium content. Journal of Family Ecology \& Consumer Sciences, 31, 12-20.

Mattes, R. D. (1997). The taste for salt in humans. American Journal of Clinical Nutrition, 65, 692S-697S.

Mattes, R. D., \& Donnelly, D. (1991). Relative contributions of dietary sodium sources. Journal of the American College of Nutrition, 10(4), 383-393.

Methven, L., Langreney, E., \& Prescott, J. (2012). Changes in liking for a no added salt soup as a function of exposure. Food Quality and Preference, 26(2), 135140. doi:10.1016/j.foodqual.2012.04.012

Mitchell, M., Brunton, N. P., \& Wilkinson, M. G. (2013). The influence of salt taste threshold on acceptability and purchase intent of reformulated reduced sodium vegetable soups. Food Quality and Preference, 28(1), 356-360. doi:10.1016/j.foodqual.2012.11.002

Mitchell, M., Brunton, N., \& Wilkinson, M. (2009). Optimization of the sensory acceptability of a reduced salt model ready meal. Journal of Sensory Studies, 24(1), 133-147. doi:10.1111/j.1745-459X.2008.00199.x

Mohan, S., \& Campbell, N. R. C. (2009). Salt and high blood pressure. Clinical Science, 117(1), 1-11. doi:10.1042/CS20080207

Newson, R. S., Elmadfa, I., Biro, G., Cheng, Y., Prakash, V., Rust, P., ... Feunekes, G. I. J. (2013). Barriers for progress in salt reduction in the general population. An international study. Appetite, 71, 22-31. doi:10.1016/j.appet.2013.07.003 
Norton, G., \& Woodiwiss, A. (2011). Hypertension in Africa: Redressing the burden of cardiovascular disease using cost-effective nonpharmacological approaches. South African Heart Journal, 8, 28-36.

Prochaska, J. O., DiClemente, C. C., \& Norcross, J. C. (1992). In search of how people change: Applications to addictive behaviors. American Psychologist, 47(9), 1102-1114.

Rolls, B., Rolls, E., Rowe, E., \& Sweeney, K. (1981). Sensory specific satiety in man. Physiology \& Behavior, 27(1), 137-142. doi:10.1016/0031-9384(81)90310-3

Seedat, Y. K., \& Rayner, B. L. (2012). South African hypertension guideline 2011. South African Medical Journal, 102(1), 60-83.

South African Audience Research Foundation. (2013). SAARF AMPS® JUN 13: A new benchmark for media consumption.

Sullivan, S. A., \& Birch, L. L. (1990). Pass the Sugar, Pass the Salt: Experience Dictates Preference. Developmental Psychology, 26(4), 546-551.

Sutherland, J., Edwards, P., Shankar, B., \& Dangour, A. D. (2013). Fewer adults add salt at the table after initiation of a national salt campaign in the UK: a repeated cross-sectional analysis. The British Journal of Nutrition, 110(3), 552-8. doi:10.1017/S0007114512005430

Tobin, B. D., O'Sullivan, M. G., Hamill, R. M., \& Kerry, J. P. (2012). Effect of varying salt and fat levels on the sensory quality of beef patties. Meat Science, 91(4), 460-5. doi:10.1016/j.meatsci.2012.02.032

Tuorila-Ollikainen, H., Salovaara, H., \& Kurkela, R. (1986). Effect of saltiness on the liking and consumption of bread and butter. Ecology Food Nutrition, 18, 99-106.

Wang, C., Lee, Y., \& Lee, S.-Y. (2014). Consumer acceptance of model soup system with varying levels of herbs and salt. Journal of Food Science, 79(10), S2098106. doi:10.1111/1750-3841.12637

Webster, J. L., Dunford, E. K., Hawkes, C., \& Neal, B. C. (2011). Salt reduction initiatives around the world. Journal of Hypertension, 29(6), 1043-50. doi:10.1097/HJH.0b013e328345ed83

Welsh, D., Lennie, T. A., Marcinek, R., Biddle, M. J., Abshire, D., Bentley, B., \& Moser, D. K. (2013). Low-sodium diet self-management intervention in heart failure: pilot study results. European Journal of Cardiovascular Nursing : Journal of the Working Group on Cardiovascular Nursing of the European Society of Cardiology, 12(1), 87-95. doi:10.1177/1474515111435604

Wentzel-Viljoen, E., Steyn, K., Ketterer, E., \& Charlton, K. (2013). Use salt and foods high in salt sparingly": a food-based dietary guideline for South Africa. South African Journal of Clinical Nutrition, 26(3), Supplement S105.

Willems, A. A., van Hout, D. H. A., Zijlstra, N., \& Zandstra, E. H. (2014). Effects of salt labelling and repeated in-home consumption on long-term liking of reduced- 
salt soups. Public Health Nutrition, 17(5), 1130-7.

doi:10.1017/S1368980013001055

World Health Organisation. (2007). Reducing salt intake in populations. Report of a WHO Forum and Technical Meeting. Geneva, Switzerland.

World Health Organisation. (2012). Guideline: Sodium intake for adults and children. Retrieved from

http://www.who.int/nutrition/publications/guidelines/sodium_intake/en/

Zandstra, E. H., De Graaf, C., Mela, D. J., \& Van Staveren, W. A. (2000). Short- and long-term effects of changes in pleasantness on food intake. Appetite, 34(3), 253-60. doi:10.1006/appe.1999.0304.

Zandstra, E.H., Lion, R. \& Newson, R.S. (2015). Salt reduction: Moving from consumer awareness to action. Food Quality \& Preference. Advance online publication. http://dx.doi.org/10.1016/j.foodqual.2015.03.005. 